\title{
Ação do Anidrido Naftálico na Seletividade de Herbicidas Aplicados para Controle de AZeVÉm em AVeia-Branca ${ }^{1}$
}

\author{
Action of Naphthalic Anhydride on Herbicide Selected for Ryegrass Control in Oat
}

RIZZARDI, M.A. ${ }^{2}$ e SERAFINI, M.C. ${ }^{3}$

\begin{abstract}
RESUMO - Um experimento foi conduzido em Passo Fundo-RS, com o objetivo de avaliar os efeitos do tratamento de sementes de aveia-branca (Avena sativa) com o antídoto anidrido naftálico (AN) na seletividade de herbicidas utilizados para controle de azevém (Lolium multiflorum). O delineamento experimental utilizado foi em parcelas subdivididas, em blocos casualizados, repetidos quatro vezes. As parcelas principais foram constituídas pela ausência ou presença do AN $\left(5 \mathrm{~g} \mathrm{~kg}^{-1}\right)$ no tratamento das sementes de aveia, e nas subparcelas foram alocados cinco tratamentos herbicidas, uma testemunha sem azevém e sem aplicação de herbicida e uma testemunha sem controle de azevém. Os tratamentos herbicidas utilizados foram diclofop (284 e $426 \mathrm{~g} \mathrm{ha}^{-1}$ ), sulfentrazone (600 $\mathrm{g} \mathrm{ha}^{-1}$ ), isoxaflutole $\left(52,5 \mathrm{~g} \mathrm{ha}^{-1}\right)$ e clomazone ( $\left.1.000 \mathrm{~g} \mathrm{ha}^{-1}\right)$. Foram avaliados o percentual de controle de azevém, a fitotoxicidade visual dos herbicidas e as características associadas à cultura da aveia, como massa seca da parte aérea, altura de planta, número de plantas e de panículas por área, peso de 1.000 grãos e rendimento de grãos. Os resultados evidenciaram que o tratamento de sementes de aveia com AN não aumentou a seletividade dos herbicidas aplicados, com exceção para massa seca da parte aérea, no caso de sulfentrazone. Os herbicidas que propiciaram os melhores níveis de controle de azevém foram os que ocasionaram maiores danos fitotóxicos à cultura da aveia-branca.
\end{abstract}

Palavras-chave: Avena sativa, antídoto, fitotoxicidade, rendimento de grãos.

\begin{abstract}
An experiment was conducted in Passo Fundo, Rio Grande do Sul, Brazil, to evaluate the effects of treatment of oat seeds (Avena sativa) with naphthalic anhydride safener (AN) on the herbicide selectivity used for ryegrass (Lolium multiflorum) control. The experimental design used was a split-plot one, in randomized blocks, with four replications. The treatments consisted of oat seed treated or not with AN $\left(5 \mathrm{~g} \mathrm{~kg}^{-1}\right.$ seed $)$ as main plots, and of five herbicide treatments, one check without ryegrass and herbicide and one check without ryegrass control, as sub plots. Herbicide treatment used were diclofop (284 e $\left.426 \mathrm{~g} \mathrm{ha}^{-1}\right)$, sulfentrazone $\left(600 \mathrm{~g} \mathrm{ha}^{-1}\right)$, isoxaflutole $\left(52,5 \mathrm{~g} \mathrm{ha}^{-1}\right)$ and clomazone (1000 $\left.\mathrm{g} \mathrm{ha}^{-1}\right)$. Ryegrass percentage control, visual phytotoxicity of herbicides and characteristics associated with the oat crop as shoot dry weight, plant height, number of plants and panicles per area, weight of 1000 grains and grain yield were evaluated. Results showed that treatment of oat seeds did not increase herbicide selectivity, with exception of shoot dry weight, for the sullfentrazone. Herbicides that provided the best ryegrass control level caused the greatest phytotoxic damage to the oat crop.
\end{abstract}

Key words: Avena sativa, safener, plant injury, grain yield.

Recebido para publicação em 31/8/2001 e na forma revisada em 17/12/2001.

2 Eng.-Agrônomo, Mestre, Professor da Faculdade de Agronomia e Medicina Veterinária da Universidade de Passo Fundo (UPF). Caixa Postal 611, 99001-970 Passo Fundo-RS, <rizzardi@upf.tche.br>; ${ }^{3}$ Acadêmico do Curso de Agronomia da UPF.

Planta Daninha, Viçosa-MG, v.19, n.3, p.367-374, 2001 


\section{INTRODUÇÃO}

As aveias são importantes alternativas de culturas de inverno na região Sul do Brasil, sendo utilizadas tanto para produção de grãos quanto para estabelecimento de pastagem e cobertura do solo. Entre as aveias disponíveis, a aveia-branca (Avena sativa) tem ampliado seu cultivo, surgindo, em conseqüência, problemas relacionados à presença de plantas daninhas, como azevém (Lolium multiflorum).

O controle seletivo de azevém quando em ocorrência em cereais de inverno, como trigo, pode ser obtido pela aplicação do herbicida diclofop (Vargas \& Fleck, 1999). Em trigo, esse herbicida é rapidamente detoxificado pela produção de ao menos três metabólitos, os quais são rapidamente conjugados (Ahrens, 1994). Essas reações envolvem um complexo de enzimas denominado monooxigenase citocromo P-450, as quais catalisam as reações de hidroxilação que levam à detoxificação rápida de diclofop (Holt et al., 1993). Em raízes de aveia, a forma ácida de diclofop é primeiramente conjugada ao grupo carboxil para formar éster de glicose, o qual não é fitotóxico, mas pode ser rapidamente hidrolisado e produzir diclofop ácido ativo (Ahrens, 1994). Assim, a produção de éster de glicose não protege as plantas de aveia da toxicidade de diclofop, não sendo, portanto, esse herbicida uma alternativa de controle seletivo de azevém na cultura da aveia. Ao testarem genótipos de aveia-branca, Vargas et al. (1998) constataram, em experimento em vasos, diferenças na seletividade do herbicida diclofop entre genótipos; entretanto, no experimento em campo a aveia-branca não produziu grãos quando tratada com diclofop.

A seletividade de um herbicida à cultura está relacionada a uma série de fatores, como características do herbicida e das plantas e métodos de aplicação (Oliveira Jr., 2001). A seletividade do herbicida pode ser melhorada com a utilização de antídotos (Robinson et al., 1994; Jablonkai \& Dutka, 1995). Antídotos protegem as plantas da cultura do dano herbicida sem reduzir a atividade nas espécies-alvo. Em 1971, foi desenvolvido o 1,8 anidrido naftálico (AN), sendo considerado o primeiro antídoto comercial a ser utilizado para proteção das sementes de milho contra a injúria causada pelos herbicidas tiocarbamatos (Davies \& Caseley, 1999).
Antídotos protegem culturas gramíneas do dano herbicida pela redução na habilidade das moléculas do herbicida em atingirem e ligaremse ao local de ação na cultura (Kotoula-Syka \& Hatzios, 1996). Esses autores demonstraram que a tolerância de milho aos herbicidas do grupo químico das sulfoniluréias pode ser aumentada com o uso do antídoto AN. Resultados semelhantes para milho são relatados por Boldt \& Barrett (1991) e Robinson et al. (1994) e para Avena fatua por Joseph et al. (1990). Teoricamente, o aumento na tolerância ao uso de antídotos pode ser conseguido por estímulo do metabolismo herbicida em enzimas-alvo, redução na absorção e translocação do herbicida, ou metabolização do herbicida a compostos menos tóxicos (Davies \& Caseley, 1999).

Ao testarem o potencial de uso do AN em milho, Davies et al. (1998) não observaram redução na concentração interna do herbicida para níveis não-fitotóxicos. Assim, a inibição da absorção pode não ser o mecanismo predominante para a ação desse antídoto. Segundo os autores, outras observações do efeito de antídotos em processos de absorção são contraditórias, sendo relatados resultados em que AN tanto aumenta quanto diminui a absorção do herbicida. Em outro trabalho, Kotoula-Syka \& Hatzios (1996) associaram a ação protetora do AN com o aumento no metabolismo oxidativo do herbicida nas plantas tratadas com o antídoto.

Os antídotos estimulam, principalmente, a atividade da enzima glutationa transferase, responsável pela conjugação de herbicidas com glutationa (Edwards, 1996). Além disso, antídotos também têm sido associados ao aumento na tolerância da cultura a herbicidas expostos a reações oxidativas do metabolismo, as quais são catalisadas pela citocromo P-450 ligada ao retículo endoplasmático liso (Davies et al., 1998). Esse complexo de enzimas é induzido por uma série de compostos, como herbicidas e antídotos (Davies \& Caseley, 1999), os quais podem ser utilizados para estimular a atividade da citocromo P-450 em plantas, como obtido com o uso de AN em milho por Hinz et al. (1997).

Devido à sua habilidade de aumentar a seletividade da cultura, os antídotos têm distintos potenciais de uso, que incluem a proteção das culturas contra os danos causados por resíduos 
de herbicidas e o uso de herbicidas sob condições adversas, onde o dano na cultura é provável de ocorrer (Davies \& Caseley, 1999). Nesse contexto, incluem-se dificuldades de controle de ervas botanicamente relacionadas com a cultura, como é o caso da ocorrência de azevém na cultura da aveia-branca. Para esta cultura, o controle de azevém, por razões técnicas e econômicas, é improvável de ser solucionado a curto e médio prazo pelo desenvolvimento de herbicidas seletivos. De outro modo, a evolução no conhecimento do mecanismo de ação dos antídotos (Davies \& Caseley, 1999) e a associação de sua ação com processos de detoxificação de herbicidas (Davies et al., 1998) fazem com que seja esperada a ocorrência de ação protetora para uma gama maior de herbicidas que possuam metabolização associada a citocromo P-450, como diclofop, ou mesmo com outros herbicidas com diferentes mecanismos de ação, como clomazone, sulfentrazone e isoxaflutole, e que são eficientes no controle de gramíneas.

O objetivo deste experimento foi avaliar o efeito do tratamento de sementes de aveiabranca (Avena sativa) com o antídoto AN na seletividade de herbicidas utilizados para o controle de azevém (Lolium multiflorum).

\section{MATERIAL E MÉTODOS}

O experimento foi conduzido em campo no Centro de Extensão e Pesquisa Agronômica da Universidade de Passo Fundo (Cepagro/UPF), localizado no município de Passo Fundo, região fisiográfica do Planalto Médio do Rio Grande do Sul. O solo da área experimental é classificado como Latossolo Vermelho Distrófico típico (EMBRAPA, 1999), textura argilosa.

O delineamento experimental utilizado foi o de blocos casualizados, com os tratamentos arranjados em parcelas subdivididas, com quatro repetições. As parcelas principais foram constituídas pela ausência ou presença do anidrido naftálico (AN) no tratamento das sementes de aveia. Nas subparcelas, foram alocados cinco tratamentos herbicidas, uma testemunha sem azevém e sem aplicação de herbicida e uma testemunha sem controle de azevém. Os tratamentos herbicidas utilizados foram diclofop (284 e $426 \mathrm{~g} \mathrm{ha}^{-1}$ ), sulfentrazone (600 $\mathrm{g} \mathrm{ha}^{-1}$ ), isoxaflutole $\left(52,5 \mathrm{~g} \mathrm{ha}^{-1}\right)$ e clomazone (1.000 $\left.\mathrm{g} \mathrm{ha}^{-1}\right)$. A área total de cada subparcela foi de $15 \mathrm{~m}^{2}(3,0 \times 5,0 \mathrm{~m})$.
O tratamento de sementes de aveia-branca foi realizado manualmente, com a mistura de $5 \mathrm{~g}$ de $\mathrm{AN} \mathrm{kg}^{-1}$ de semente. O cultivar utilizado foi o UPF-16. Após tratadas, procedeu-se à semeadura direta da aveia com semeadora de precisão, em 2/7/97. A densidade de semeadura foi de 300 sementes aptas $\mathrm{m}^{-2}$, em espaçamento de 0,2 m entre linhas. A adubação foi feita com base nos resultados da análise físicoquímica do solo, através da distribuição de $300 \mathrm{~kg} \mathrm{ha}^{-1}$ da fórmula 05-20-20, por ocasião da semeadura da cultura. A adubação de cobertura, realizada no perfilhamento da aveia, constou de $45 \mathrm{~kg}$ de $\mathrm{N} \mathrm{ha}^{-1}$ na forma de uréia.

A aplicação dos herbicidas foi realizada em pré-emergência da cultura, um dia após a semeadura. Para realizar as aplicações do herbicida, utilizou-se pulverizador costal de precisão, equipado com bicos de jato plano, em leque, série 110.02 , espaçados de $50 \mathrm{~cm}$ entre si. O volume de calda herbicida aplicado foi de $150 \mathrm{~L} \mathrm{ha}^{-1}$. No momento da aplicação dos herbicidas a temperatura atmosférica média era de $16,8{ }^{\circ} \mathrm{C}$ e a umidade relativa do ar de $92 \%$, com ausência de ventos e boa umidade do solo. As condições de precipitação pluvial após a aspersão dos herbicidas foram consideradas normais para o período do ano.

A emergência das plântulas da cultura ocorreu sete dias após a semeadura (9/7/97). A população média de azevém presente na área, em avaliação realizada 15 dias após a emergência da aveia, em área de $1,0 \mathrm{~m}^{2}$ por parcela, foi de 48 plantas $\mathrm{m}^{-2}$.

As avaliações visuais de fitotoxicidade foram realizadas aos 15 e 30 dias após a aspersão dos herbicidas (DAA). Para a avaliação de danos visuais, foi utilizada escala percentual, na qual a nota 0 significou ausência de dano à cultura e a nota 100 , morte aparente das plantas. Por ocasião da primeira avaliação de fitotoxicidade, fez-se a contagem do número de plantas de aveia, em duas áreas de $1 \mathrm{~m}^{2}$ de cada subparcela.

Os percentuais de controle obtidos pelos tratamentos herbicidas foram avaliados aos 15 e 30 DAA. Para isso, utilizou-se escala percentual, em que 0 correspondeu a nenhum efeito de controle e a nota 100 significou morte completa do azevém. Aos 48 DAA, quando as plantas de aveia encontravam-se no início do afilhamento, foram coletadas plantas para 
avaliação da massa seca da parte aérea, em $1 \mathrm{~m}^{2}$ de cada subparcela. Após a coleta, as plantas foram postas a secar em estufa com circulação forçada de ar à temperatura de $70{ }^{\circ} \mathrm{C}$, até atingir peso constante, quando então foram pesadas.

No final do florescimento da cultura fez-se avaliação da altura das plantas, medindo-se a distância entre o nível do solo e o ápice da panícula da aveia, em dez plantas por subparcela.

O número de panículas foi avaliado na précolheita da cultura, em área de $1 \mathrm{~m}^{2}$ de cada subparcela. O rendimento de grãos da aveia foi determinado numa área amostrada de $2 \mathrm{~m}^{2}$ ( $1 \times 2 \mathrm{~m}$ ), englobando cinco fileiras centrais das subparcelas. Após a pesagem dos grãos colhidos, corrigiu-se sua umidade para $13 \%$, sendo os resultados finais expressos em $\mathrm{kg} \mathrm{ha}^{-1}$. O peso de 1.000 grãos foi determinado em 10 plantas colhidas aleatoriamente na parte central das subparcelas, fora da área utilizada na determinação do rendimento de grãos.

Os resultados obtidos foram submetidos à análise de variância e, quando significativas, as médias foram comparadas pelo teste de Tukey, a 5\% de probabilidade. Para análise de variância, os valores expressos em porcentagem foram transformados para raiz quadrada de $(x+0,5)$.

\section{RESULTADOS E DISCUSSÃO}

Os níveis de controle de azevém obtidos variaram entre os tratamentos herbicidas, independentemente do tratamento de sementes com AN (Tabela 1). A ausência de influência do uso de antídotos na eficiência de controle de ervas é relatada por outros autores (Davies \& Caseley, 1999), e essa característica é justamente uma das principais razões para o uso de antídotos, ou seja, proteger a cultura do dano herbicida sem reduzir a eficácia herbicida nas ervas-alvo.

Os melhores niveis de controle foram obtidos com o uso de clomazone e sulfentrazone, e os piores, com o herbicida isoxaflutole, tanto aos 15 quanto aos 30 DAA. Entre os herbicidas mais eficientes no controle de azevém, somente clomazone é recomendado para ser utilizado seletivamente em culturas gramíneas, e, no caso, somente em cana-de-açúcar e arroz (Rodrigues \& Almeida, 1998). No arroz, clomazone causa danos de fitotoxicidade nos estádios iniciais, logo após aplicação, os quais desaparecem ao longo do desenvolvimento da cultura (Carvalho et al., 2000). De outra parte, resultados de pesquisa mostraram que isoxaflutole apresenta elevado controle de gramíneas anuais, como Setaria faberi (Young \& Hart, 1998) e Brachiaria plantaginea (Spader \& Vidal, 2000), o que não foi observado neste experimento para azevém.

Tabela 1 - Avaliações de controle de azevém e fitotoxicidade de herbicidas aplicados em pré-emergência em aveia-branca, na média de tratamento de sementes com anidrido naftálico. FAMV/UPF, Passo Fundo-RS, 1997

\begin{tabular}{|c|c|c|c|c|c|}
\hline \multirow{2}{*}{ Tratamentos } & \multirow{2}{*}{$\begin{array}{c}\text { Doses } \\
\left(\mathrm{g} \mathrm{ha}^{-1}\right)\end{array}$} & \multicolumn{2}{|c|}{ Controle de azevém (\%) } & \multicolumn{2}{|c|}{ Fitotoxicidade $(\%)$} \\
\hline & & $15 \mathrm{DAA}^{1 /}$ & 30 DAA & 15 DAA & 30 DAA \\
\hline diclofop & 426 & $79 \mathrm{~b}^{-1}$ & $86 \mathrm{~b}$ & $12 \mathrm{c}$ & $15 \mathrm{~cd}$ \\
\hline diclofop & 284 & $78 \mathrm{~b}$ & $83 \mathrm{~b}$ & $12 \mathrm{c}$ & $14 \mathrm{~cd}$ \\
\hline sulfentrazone & 600 & $95 \mathrm{a}$ & $97 \mathrm{a}$ & $40 \mathrm{~b}$ & $50 \mathrm{~b}$ \\
\hline isoxaflutole & 52,5 & $23 \mathrm{c}$ & $22 \mathrm{c}$ & $17 \mathrm{c}$ & $20 \mathrm{c}$ \\
\hline clomazone & 1000 & $99 \mathrm{a}$ & $99 \mathrm{a}$ & $73 \mathrm{a}$ & $80 \mathrm{a}$ \\
\hline testemunha sem erva & ----- & $100 \mathrm{a}$ & $100 \mathrm{a}$ & $00 \mathrm{~d}$ & $00 \mathrm{~d}$ \\
\hline testemunha sem controle & ----- & $00 \mathrm{~d}$ & $00 \mathrm{~d}$ & $00 \mathrm{~d}$ & $00 \mathrm{~d}$ \\
\hline $\mathrm{CV}(\%)$ & & 1,9 & 1,5 & 5,3 & 6,7 \\
\hline F antídoto & & $0,277 \mathrm{~ns}$ & $0,143 \mathrm{~ns}$ & $0,65 \mathrm{~ns}$ & $0,13 \mathrm{~ns}$ \\
\hline F herbicida & & $842,03 *$ & $1.980,00 *$ & $52,54 *$ & $43,25 *$ \\
\hline $\mathrm{F}$ antídoto $\mathrm{x}$ herbicida & & $0,79 \mathrm{~ns}$ & $0,69 \mathrm{~ns}$ & $1,14 \mathrm{~ns}$ & $0,98 \mathrm{~ns}$ \\
\hline
\end{tabular}

${ }^{1 /}$ Dias após aplicação do herbicida; ${ }^{2} /$ médias seguidas de letras idênticas não diferem estatisticamente pelo teste de Tukey a $5 \%$ de probabilidade; ${ }^{\text {ns }}$ não-significativo a $5 \%$ de probabilidade; $*$ significativo a $5 \%$ de probabilidade. 
Em relação ao diclofop, não se observaram diferenças nos níveis de controle de azevém entre doses de 284 e $486 \mathrm{~g} \mathrm{ha}^{-1}$, porém o controle foi inferior ao observado por Vargas \& Fleck (1999). Embora existam indicações para uso de diclofop em aplicação de pré-emergência (Ahrens, 1994), a aplicação preferencial deste herbicida dá-se em pós-emergência, quando as ervas apresentam duas a seis folhas (CSBPT, 2000). Como o diclofop foi aplicado em préemergência, é possível que tenha ocorrido diminuição na eficiência de controle pela mudança na época de aplicação. Especulava-se, quando da concepção do experimento, que, pelo fato de o herbicida diclofop apresentar controle inferior de aveia em relação ao azevém e necessitar de dose mais alta para seu controle (CSBPT, 2000), poder-se-ia manter controle de azevém, diminuindo o efeito sobre a aveia, no momento da aplicação em pré-emergência.

A avaliação visual de fitotoxicidade, procedida aos 15 e 30 DAA, indicou não haver interação do uso de antídoto e tratamento herbicida (Tabela 1). A ausência de interação contradiz os resultados obtidos em outros estudos com aveia-branca e milho (Codd, 1986; Hinz et al., 1997; Boldt \& Barrett, 1991). Verificou-se que, dentre os herbicidas, os que provocaram maior efeito fitotóxico foram clomazone e sulfentrazone, justamente aqueles que propiciaram controle mais eficiente de azevém. Os demais tratamentos herbicidas causaram efeitos que variaram de 12 a $20 \%$. Os resultados médios de fitotoxicidade, obtidos com o herbicida diclofop, estão de acordo com os valores médios relatados por Vargas et al. (1998), ao testarem genótipos de aveia-branca em condições controladas, porém bem inferiores aos relatados por esses mesmos autores quando em experimento conduzido em campo. Parte desses resultados pode estar associada às diferenças na tolerância ao herbicida entre os cultivares utilizados nos experimentos. No caso do UPF-16, Vargas et al. (1998) constataram efeitos fitotóxicos que variaram de 8 a 10\% ao aplicarem $284 \mathrm{~g} \mathrm{ha}^{-1}$ de diclofop em pós-emergência; portanto, bastante semelhantes aos obtidos neste experimento. Em outra pesquisa, Vargas \& Fleck (1999) relataram danos de 38 a 97\% no cultivar UPF-16 após aplicação de $540 \mathrm{~g} \mathrm{ha}^{-1}$ de diclofop.

A avaliação de massa seca da parte aérea de aveia indicou haver interação do uso de antídoto e tratamentos herbicidas (Tabela 2). Na presença do antídoto, excetuando clomazone, todos os demais herbicidas propiciaram produções de massa seca semelhantes às observadas tanto na testemunha sem erva quanto na testemunha sem controle. Na ausência do antídoto, houve maior diferenciação entre os herbicidas. Para o herbicida sulfentrazone, o uso de AN propiciou aumento de 2,5 vezes na produção de massa seca, em relação ao tratamento sem AN. A principal rota de metabolização de sulfentrazone, em plantas tolerantes, envolve a hidroxilação oxidativa do herbicida, a qual pode ser associada à atividade da citocromo P-450 (Dayan et al., 1997). Assim, é possivel que o uso de AN nas sementes de aveia tenha induzido a atividade da citocromo P-450, como observado por Hinz et al. (1997) na parte aérea de milho. No entanto, essa proteção não foi suficiente para eliminar o efeito fitotóxico visual desse herbicida, como constatado na Tabela 1.

Tabela 2 - Efeitos de aplicações de herbicidas e do uso de anidrido naftálico na massa seca da parte aérea de plantas de aveia-branca. FAMV/UPF, Passo Fundo-RS, 1997

\begin{tabular}{|c|c|c|c|}
\hline \multirow[t]{2}{*}{ Tratamentos } & \multirow{2}{*}{$\begin{array}{l}\text { Doses } \\
\left(\mathrm{g} \mathrm{ha}^{-1}\right)\end{array}$} & \multicolumn{2}{|c|}{$\begin{array}{c}\text { Massa seca da parte aérea } \\
\qquad\left(\mathrm{g} \mathrm{m}^{-2}\right)\end{array}$} \\
\hline & & Com antídoto & Sem antídoto \\
\hline diclofop & 426 & A $171 a^{1 /}$ & A 174 abc \\
\hline diclofop & 284 & В $108 \mathrm{ab}$ & A $219 a b$ \\
\hline sulfentrazone & 600 & A $121 \mathrm{ab}$ & B $49 \mathrm{~d}$ \\
\hline isoxaflutole & 52,5 & A $110 a b$ & A $97 \mathrm{~cd}$ \\
\hline clomazone & 1000 & A $23 \mathrm{~b}$ & A $34 \mathrm{~d}$ \\
\hline testemunha sem erva & ----- & B $161 \mathrm{a}$ & A 237 a \\
\hline testemunha sem controle & ----- & A 166 a & A $125 \mathrm{abc}$ \\
\hline \multicolumn{4}{|l|}{ CV antídoto $(\%)=5,4$} \\
\hline \multicolumn{4}{|l|}{$\mathrm{CV}$ herbicidas $(\%)=12,7$} \\
\hline \multicolumn{4}{|l|}{$\mathrm{F}$ antídoto $=0,65^{\mathrm{ns}}$} \\
\hline \multicolumn{4}{|l|}{$\mathrm{F}$ herbicida $=13,66^{*}$} \\
\hline $\mathrm{F}$ antídoto $\mathrm{x}$ herbicida $=3,95^{*}$ & & & \\
\hline
\end{tabular}

${ }^{1 /}$ Médias antecedidas por letras maiúsculas (na linha) ou seguidas por letras minúsculas (na coluna) idênticas não diferem estatisticamente pelo teste de Tukey a $5 \%$ de probabilidade; ns nãosignificativo a $5 \%$ de probabilidade; * significativo a $5 \%$ de probabilidade.

As características número e altura de plantas de aveia e número de panículas não foram influenciadas pela interação do tratamento de sementes e os herbicidas aspergidos (Tabela 3). De maneira geral, os tratamentos herbicidas influenciaram pouco o número de plantas de 
aveia, o que era esperado, pelo fato de o mecanismo de ação principal desses herbicidas não ser a inibição da emergência das plantas sensíveis, embora existam relatos de redução na densidade de plantas de papuã após o tratamento com isoxaflutole (Spader \& Vidal, 2000). Excetuando o herbicida clomazone, em todos os demais tratamentos herbicidas o número de plantas emergidas foi igual ao da testemunha sem erva. Os resultados obtidos para número de panículas foram semelhantes aos relatados para número de plantas; porém, para essa variável, além do efeito negativo do clomazone, houve redução de $23 \%$ no tratamento com isoxaflutole, em relação à testemunha sem erva. O número de panículas por área foi a única variável, associada à cultura da aveia, que foi negativamente influenciada pelo uso do herbicida isoxaflutole. Para altura de planta, as maiores reduções foram observadas para os herbicidas clomazone e sulfentrazone, os quais reduziram a altura em 91 e $24 \%$ em relação à testemunha sem erva, respectivamente (Tabela 3); já para o herbicida diclofop as reduções foram de $7 \%$, na média das duas doses utilizadas. Esses resultados de altura estão em conformidade com os observados para fitotoxicidade (Tabela 1).

Com relação ao peso de 1.000 grãos, houve variação entre os tratamentos herbicidas, independentemente do tratamento de sementes com AN (Tabela 3). Na média do uso de antídoto, foram observadas reduções nessa variável nos tratamentos com os herbicidas clomazone e sulfentrazone. Quando do uso do herbicida clomazone não houve formação de grãos; já com o uso de sulfentrazone a redução foi de $8 \%$ em relação à testemunha sem erva. Para os demais tratamentos herbicidas, o peso de grãos foi similar ao obtido na testemunha sem erva e sem controle.

A análise de variância não evidenciou interação do uso de antídoto e os herbicidas na avaliação de rendimento de grãos (Tabela 4). $\mathrm{O}$ rendimento médio obtido na presença ou ausência de AN foi de 844 e $845 \mathrm{~kg} \mathrm{ha}^{-1}$, respectivamente. Excetuando o tratamento com o herbicida clomazone, em que a produção foi nula, todos os demais tratamentos herbicidas propiciaram rendimentos de grãos semelhantes ao da testemunha sem erva e sem herbicida. Os resultados de rendimento de grãos obtidos com o uso de diclofop contradizem os observados por Vargas et al. (1998), para os quais, com a aplicação de $355 \mathrm{~g} \mathrm{ha}^{-1}$ de diclofop, em pós-emergência, não foi possível a colheita de grãos. Provavelmente, os menores danos de fitotoxicidade causados pela aspersão do herbicida em pré-emergência justificam essas diferenças (Tabela 1). O rendimento de grãos obtido quando da aplicação de sulfentrazone foi surpreendente, uma vez que a fitotoxicidade, a estatura de planta e o peso de 1.000 grãos foram sempre inferiores aos observados nas

Tabela 3 - Efeitos de aplicações de herbicidas em características de plantas de aveia-branca, na média de tratamento de sementes com anidrido naftálico. FAMV/UPF, Passo Fundo-RS, 1997

\begin{tabular}{|l|c|c|c|c|c|}
\hline \multicolumn{1}{|c|}{ Tratamentos } & $\begin{array}{c}\text { Doses } \\
\left(\mathrm{g} \mathrm{ha}^{-1}\right)\end{array}$ & $\begin{array}{c}\text { Plantas } \\
\left(\mathrm{n}^{\mathrm{o}} \mathrm{m}^{-2}\right)\end{array}$ & $\begin{array}{c}\text { Estatura } \\
(\mathrm{cm})\end{array}$ & $\begin{array}{c}\text { Panículas } \\
\left(\mathrm{n}^{\mathrm{o}} \mathrm{m}^{-2}\right)\end{array}$ & $\begin{array}{c}\text { Peso de } 1.000 \\
\mathrm{grãos}(\mathrm{g})\end{array}$ \\
\hline diclofop & 426 & $256 \mathrm{a}^{\underline{1}}$ & $87,4 \mathrm{ab}^{\underline{1}}$ & $252 \mathrm{ab}^{\underline{1}}$ & $26,2 \mathrm{ab}^{\underline{1}}$ \\
diclofop & 284 & $230 \mathrm{ab}$ & $88,4 \mathrm{a}$ & $247 \mathrm{ab}$ & $24,6 \mathrm{ab}^{\prime}$ \\
sulfentrazone & 600 & $214 \mathrm{ab}$ & $71,5 \mathrm{~b}$ & $222 \mathrm{ab}$ & $22,9 \mathrm{~b}$ \\
isoxaflutole & 52,5 & $217 \mathrm{ab}$ & $85,0 \mathrm{ab}$ & $210 \mathrm{~b}$ & $28,7 \mathrm{a}$ \\
clomazone & 1000 & $154 \mathrm{c}$ & $8,5 \mathrm{c}$ & $00 \mathrm{c}$ & $00 \mathrm{c}$ \\
testemunha sem erva & ---- & $211 \mathrm{ab}$ & $93,6 \mathrm{a}$ & $273 \mathrm{a}$ & $24,7 \mathrm{ab}$ \\
testemunha sem controle & ---- & $203 \mathrm{bc}$ & $88,9 \mathrm{a}$ & $212 \mathrm{ab}$ & $28,5 \mathrm{a}$ \\
\hline CV $(\%)$ & & 4,6 & 7,5 & 9,1 & 5,4 \\
\hline F antídoto & & $2,77^{\mathrm{ns}}$ & $0,02^{\mathrm{ns}}$ & $0,11^{\mathrm{ns}}$ & $4,83^{\text {ns }}$ \\
F herbicida & $6,79 *$ & $68,61^{*}$ & $45,22^{*}$ & $96,02^{\text {n }}$ \\
F antídoto x herbicida & $1,02^{\mathrm{ns}}$ & $1,66^{\mathrm{ns}}$ & $0,96^{\mathrm{ns}}$ & $0,97^{\mathrm{ns}}$ \\
\hline
\end{tabular}

${ }^{1 /}$ Médias seguidas de letras idênticas não diferem estatisticamente pelo teste de Tukey a $5 \%$ de probabilidade; ${ }^{\text {ns }}$ não-significativo a $5 \%$ de probabilidade; * significativo a $5 \%$ de probabilidade. 
plantas da testemunha sem erva. No entanto, esse herbicida não influenciou o número de plantas e de panículas por área; é provável que essas variáveis tenham compensado os efeitos negativos nas demais variáveis.

Tabela 4 - Efeitos de aplicações de herbicidas e do uso de anidrido naftálico no rendimento de grãos de aveiabranca. FAMV/UPF, Passo Fundo-RS, 1997

\begin{tabular}{|c|c|c|c|c|}
\hline \multirow{2}{*}{ Tratamentos } & \multirow{2}{*}{$\begin{array}{l}\text { Doses } \\
\left(\mathrm{g} \mathrm{ha}^{-1}\right)\end{array}$} & \multicolumn{3}{|c|}{$\begin{array}{c}\text { Rendimento de grãos } \\
\left(\mathrm{kg} \mathrm{ha}^{-1}\right)\end{array}$} \\
\hline & & $\begin{array}{c}\text { Com } \\
\text { antídoto }\end{array}$ & $\begin{array}{c}\text { Sem } \\
\text { antídoto }\end{array}$ & Médias \\
\hline diclofop & 426 & 946 & 1.066 & $977 \mathrm{a}^{\mathbf{1}^{1 /}}$ \\
\hline diclofop & 284 & 935 & 1.012 & 974 a \\
\hline sulfentrazone & 600 & 957 & 770 & 864 a \\
\hline isoxaflutole & 52,5 & 964 & 1.149 & $1.056 \mathrm{a}$ \\
\hline clomazone & 1000 & 00 & 00 & $00 \mathrm{~b}$ \\
\hline testemunha sem erva & --- & 1.152 & 929 & $1.041 \mathrm{a}$ \\
\hline testemunha sem controle & ----- & 882 & 992 & 937 a \\
\hline \multicolumn{5}{|l|}{$\mathrm{CV}$ antídoto $(\%)=10,6$} \\
\hline \\
\hline \multicolumn{5}{|l|}{ F antídoto $=0,01^{\text {ns }}$} \\
\hline \multicolumn{5}{|l|}{$\mathrm{F}$ herbicida $=12,58^{*}$} \\
\hline $\mathrm{F}$ antídoto $\mathrm{x}$ herbicida $=0,52^{*}$ & & & & \\
\hline
\end{tabular}

1/ Médias seguidas de letras idênticas não diferem estatisticamente pelo teste de Tukey a 5\% de probabilidade; ${ }^{\text {ns }}$ não-significativo a $5 \%$ de probabilidade; * significativo a $5 \%$ de probabilidade.

O uso de AN mostrou limitada atividade protetora na dose e no cultivar testado, apresentando melhor ação protetora somente na variável massa seca da parte aérea e para o herbicida sulfentrazone. Pesquisas adicionais devem ser conduzidas testando doses do antídoto em diferentes cultivares de aveia, visto que seu efeito é dependente do genótipo (Robinson et al., 1994) e que os genótipos de aveia apresentam tolerância diferencial a herbicidas como diclofop (Vargas et al., 1988; Vargas \& Fleck, 1999).

De forma geral, o tratamento de sementes de aveia com AN não influencia a eficiência de controle de azevém propiciada por herbicidas aplicados em pré-emergência. No entanto, os herbicidas que apresentam melhores níveis de controle são aqueles que ocasionam maior fitotoxicidade para aveia-branca.

\section{LITERATURA CITADA}

AHRENS, W.H. Herbicide handbook. 7.ed. Champaign: WSSA, 1994. 352p.
BOLDT, L.D.; BARRETT, M. Reducing imazethapyr injury to field corn (Zea mays) with naphthalic anhydride. Weed Sci., v.39, n.4, p.640-643, 1991.

CARVALHO, F.T.; CAVAZZANA, M.A.; CESTARE, M.A. Eficácia de herbicidas no controle em préemergência de plantas daninhas na cultura do arroz. R. Bras. Herbic., v.1, n.3, p. 213-217, 2000 .

CODD, T.M. 1,8-Naphthalic anhydride as a herbicide safener for cultivated oats. Pest. Sci., v.17, n.1, p.60, 1986.

COMISSÃO SUL-BRASILEIRA DE PESQUISA DE TRIGO - CSBPT. Controle de plantas daninhas. In: Recomendações da Comissão SulBrasileira de Pesquisa de Trigo. Cruz Alta: Fundacep, 2000. p.55-62.

DAVIES, J.; CASELEY, J.C.; JONES, O.T.G; BARRETT, M.; POLGE, N.D. Mode of action of naphthalic anhydride as a safener for herbicide AC 263222 in maize. Pest. Sci., v.52, n.1, p.29$38,1998$.

DAVIES, J.; CASELEY; J.C. Herbicide safeners: a review. Pest. Sci., v.55, n.11, p.1043-1058, 1999.

DAYAN, F.E.; WEETE, J.D.; DUKE, S.O.; HANCOCK, H.G. Soybean (Glycine max) cultivar differences in response to sulfentrazone. Weed Sci., v.45, n.5, p.634-641, 1997.

EDWARDS, R. Characterisation of glutathione transferases and glutathione peroxidases in pea (Pisum sativum). Physiol. Plant., v.98, n.3, p.594-604, 1996.

EMPRESA BRASILEIRA DE PESQUISA AGROPECUÁRIA - EMBRAPA. Centro Nacional de Pesquisa de Solos. Sistema brasileiro de classificação de solos. Brasília: 1999. 412p.

HINZ, J.R.R.; OWEN, M.D.K.; BARRETT, M. Nicosulfuron, pirimisulfuron, and bentazon hydroxylation by corn (Zea mays), woolly cupgrass (Eriochloa villosa), and shattercane (Sorghum bicolor) cytochrome P-450. Weed Sci., v.45, n.4, p.474-480, 1997.

HOLT, J.S.; POWLES, S.B.; HOLTUM, A.M. Mechanisms and agronomic aspects of herbicide resistance. Ann. Rev. Plant. Physiol. Plant Molec. Biol., v.44, p.203-229, 1993. 
JABLONKAI, I.; DUTKA, F. Uptake, translocation and metabolism of MG-191 safener in corn (Zea mays L.). Weed Sci., v.43, n. 1, p.169-174, 1995.

JOSEPH, O.O.; HOBBS, S.L.; JANA, S. Diclofop resistance in wild oat (Avena fatua). Weed Sci. v.38, n.6, p.475-479, 1990

KOTOULA-SYKA, E.; HATZIOS, K.K. Interactions of tribenuron with four safeners and piperonyl butoxide on corn (Zea mays). Weed Sci., v.44, n.2, p.215-218, 1996.

OLIVEIRA Jr., R.S. Seletividade de herbicidas para culturas e plantas daninhas. OLIVEIRA Jr. R.S.; CONSTANTIN, J. Plantas daninhas e seu manejo. Guaíba: Agropecuária, 2001. p. 291313.

ROBINSON, D.K.; MONKS, D.W.; BURTON, J.D. Effect of BAS 145 138, CGA 154 281, and naphthalic anhydride seed treatments on sweet corn (Zea mays) tolerance to nicosulfuron. Weed Sci., v.42, n.4, p.614-617, 1994
RODRIGUES, B.N.; ALMEIDA, F.S. Guia de herbicidas. 4.ed. Londrina: 1998. 648p.

SPADER, V.; VIDAL, R.A. Eficácia de herbicidas graminicidas aplicados em pré-emergência no sistema de semeadura direta do milho. Planta Daninha, v.18, n.2, p.373-380, 2000.

VARGAS, L.; FLECK, N.G. Seletividade de herbicidas do grupo químico dos ariloxifenoxipropionatos a cereais de inverno. Planta Daninha, v.17, n.1, p.41-51, 1999 .

VARGAS, L.; FLECK, N.G.; CUNHA, M.M.; VIDAL, R.A. Efeito de herbicidas graminicidas, aplicados em pós-emergência, sobre aveia-branca, aveiapreta e trigo. Planta Daninha, v.16, n.1, p.59$66,1998$.

YOUNG, B.G.; HART, S.E. Optimizing foliar activity of isoxaflutole on giant foxtail (Setaria faberi) with various adjuvants. Weed Sci., v.46, n.3, p.397$402,1998$. 